\title{
HISTOCHEMICAL OBSERVATIONS ON THE MOUSE UTERUS DURING THE OESTROUS CYCLE
}

\author{
M. S. R. SMITH* \\ Department of Zoology, The University, Southampton
}

(Received 26th fuly 1969)

\begin{abstract}
Summary. Changes in the uterus of the mouse during the oestrous cycle have been examined histochemically to demonstrate any variation in the occurrence of acid phosphatase, lipids and polysaccharide complexes (PAS-positive material) mainly with reference to the epithelium. Acid phosphatase was shown to have a distinct pattern of activity at each stage of the oestrous cycle. There was no evidence for acid phosphatase release, but a considerable build-up in large and small lysosomes was observed in the epithelium at metoestrus and di-oestrus. A different pattern was observed in the case of lipids and PAS-positive material. Lipids were found in considerable amounts at di-oestrus, pro-oestrus and metoestrus, whereas a strong PAS-positive reaction was observed at pro-oestrus and oestrus.
\end{abstract}

\section{INTRODUCTION}

Knowledge of the oestrous cycle in the mouse dates from the original study of Allen (1922). His system, which will be used in this paper, divided the cycle into five stages, as follows.

1. Di-oestrus: a period of quiescence or slow growth.

2. Pro-oestrus: an anabolic stage with considerable epithelial growth.

3. Oestrus: the same as pro-oestrus. The period $1 \mathrm{hr}$ post coitum (p.c.) was used as a control for this stage.

4. Metoestrus 1: a catabolic stage with degeneration of the uterine epithelium.

5. Metoestrus 2: the same as Metoestrus 1.

The stages of the oestrous cycle were determined by examining vaginal smears of cycling mice. The main purpose of this study was to compare and contrast the changes in acid phosphatase, lipid and polysaccharide complexes (PAS-positive material) throughout the oestrous cycle and relate these to the established histological changes.

\section{MATERIALS AND METHODS}

Twenty A $\times$ CBA hybrid females were followed by vaginal smears through three complete cycles (average $4 \frac{1}{2}$ days/cycle). They were then killed at the

* Present address: School of Anatomy, University of New South Wales, Kennington, N.S.W., Australia. 
requisite stage of the oestrous cycle (four at di-oestrus, pro-oestrus and oestrus and eight at metoestrus), fixed in $10 \%$ formol calcium $\left(4^{\circ} \mathrm{C}\right)$ for $18 \mathrm{hr}$ and transferred to sucrose solution at $4^{\circ} \mathrm{C}$. Four animals were killed at $1 \mathrm{hr}$ p.c. and treated in a similar fashion. For the routine histology controls, a small section of uterus was fixed in Clarke's acetic alcohol, sectioned at $5 \mu$ and stained with Heidenhain's iron haematoxylin.

The cold-fixed material was sectioned at 7 to $8 \mu$ on a microtome cryostat. Acid phosphatase was localized by the method of Burstone (1958); lipids were localized by the Sudan Black B method of McManus (Pearse, 1960) with a slight modification. Instead of the paraffin-embedded sections, frozen-fixed material was used. Control sections were extracted with acetone before treatment with Sudan Black B. The polysaccharide complexes were shown by the periodic acid-Schiff (PAS) method after McManus (Pearse, 1960). For the PAS sections, diastase-digested controls, using human saliva, were prepared.

All the measurements mentioned in this discussion were made on frozen formalin-fixed material.

\section{RESULTS}

The histological changes during the oestrous cycle seen in this study are similar to those described by Allen (1922) and Bronson, Dagg \& Snell (1966) and, therefore, will not be discussed further.

\section{Histochemical observations}

Acid phosphatase. Acid phosphatase-rich vacuoles (lysosomes) are found in the uterine epithelium at all stages of the oestrous cycle. Their distribution and size are summarized in Table 1. At di-oestrus (Pl. 1, Fig. 1), there appears to be an accumulation of large lysosomes in the supra- and sub-nuclear cytoplasm. The significant changes at pro-oestrus are the enlargement of the uterine lumen accompanied by an increase in the height of the uterine epithelium from $24 \mu$ at di-oestrus to $41 \mu$ at pro-oestrus. Pro-oestrus is characterized by the very numerous small lysosomes in the supranuclear cytoplasm (Pl. 1, Fig. 2): the sub-nuclear cytoplasm being similar to the di-oestrous pattern. Oestrus shows a further marked change with a fairly uniform distribution of lysosomes throughout the epithelium. The large lysosomes have disappeared and small lysosomes are predominant (Pl. 1, Fig. 3); the epithelium is $43 \mu$ high. At $1 \mathrm{hr}$ p.c., the epithelium resembles the oestrous pattern described but there is a reduction in its height to an average of $36 \mu$ and the lumen becomes very distended. At metoestrus, there appears to be a progressive disruption of the pattern with many lysosomes throughout the epithelium and many leucocytes and large vacuoles. The Metoestrus 1 (M1) stage is characterized by an infiltration of leucocytes and a little epithelial degeneration which is the main feature of Metoestrus 2 (M2). The average height of the epithelium is $36 \mu$ (PI. 1, Fig. 4).

Changes in the lysosome pattern in the glandular epithelium are not so marked. At di-oestrus, the epithelium averages $14 \mu$ in height and there is considerable acid phosphatase activity at the luminal border. Many of the glands increase their diameters at pro-oestrus and there is a small increase in the height of the epithelium. The glandular epithelium in the main resembles 
the uterine epithelium lysosome pattern at pro-oestrus and this is repeated in the other stages of the cycle (Pl. 1, Fig. 5, oestrus; Pl. 1, Fig. 6, pro-oestrus).

TABLE 1

A GOMPARISON OF THE NUMBERS AND DISTRIBUTION OF ACID PHOSPHATASE-RICH VESICLES DURING VARIOUS STAGES OF THE OESTROUS GYGLE

\begin{tabular}{|c|c|c|c|c|}
\hline & Di-oestrus & Pro-oestrus & Oestrus & $\begin{array}{l}\text { Metoestrus } \\
1 \text { and } 2\end{array}$ \\
\hline $\begin{array}{l}\text { Uterine epithelium } \\
\text { Supra-nuclear }\end{array}$ & $\begin{array}{l}++\mathrm{L} \\
+\mathrm{M} \\
+++\mathrm{S}\end{array}$ & $++++s$ & $\begin{array}{l}+\mathrm{M} \\
++\mathrm{S}\end{array}$ & $\begin{array}{l}+++\mathrm{L} \\
+++\mathrm{S}\end{array}$ \\
\hline Peri-nuclear & $<+\mathrm{S}$ & $<+\mathrm{S}$ & $++\mathrm{S}$ & $\begin{array}{l}++M \\
++S\end{array}$ \\
\hline Sub-nuclear & $\begin{array}{l}+/++L \\
+S\end{array}$ & $+1++\mathrm{L}$ & $\begin{array}{l}+\mathrm{M} \\
++\mathrm{S}\end{array}$ & $\begin{array}{l}+\mathrm{L} \\
+\mathrm{M} \\
++\mathrm{S}\end{array}$ \\
\hline $\begin{array}{l}\text { Gland epithelium } \\
\text { Supra-nuclear }\end{array}$ & $+++s$ & $\begin{array}{l}+\mathrm{L} \\
++++\mathrm{S}\end{array}$ & $\begin{array}{l}+\mathbf{M} \\
+++\mathbf{S}\end{array}$ & $\begin{array}{l}+\mathbf{M} \\
+++\mathrm{S}\end{array}$ \\
\hline Peri-nuclear & $<+\mathrm{S}$ & $<+\mathrm{s}$ & $+s$ & $+\mathrm{s}$ \\
\hline Sub-nuclear & $+\mathrm{M}$ & $\begin{array}{l}++L \\
+\stackrel{S}{L}\end{array}$ & $++s$ & $++s$ \\
\hline $\begin{array}{l}\text { Height of the uterine epithelium }(\mu) \\
\text { Height of the gland epithelium }(\mu) \\
\text { No. of stromal macrophages }\end{array}$ & $\begin{array}{l}24 \\
14 \\
12\end{array}$ & $\begin{array}{l}41 \\
20 \\
35\end{array}$ & $\begin{array}{l}43 \\
19 \\
59\end{array}$ & $\begin{array}{l}36 \\
17 \\
49\end{array}$ \\
\hline
\end{tabular}

Number of vesicles/granules: + , very few;,++ few; +++ , numerous; ++++ , very numerous.

Size of vesicles/granules: L, large $(3 \mu) ; \mathrm{M}$, medium (1 to $3 \mu) ; \mathrm{S}$, small $\langle 1 \mu)$.

TABLE 2

A COMPARISON OF THE NUMBERS AND DISTRIBUTION OF SUDANOPHILIC GRANULES DURING VARIOUS STAGES OF THE OESTROUS GYCLE

\begin{tabular}{|c|c|c|c|c|}
\hline & Di-oestrus & Pro-oestrus & Oestrus & $\begin{array}{c}\text { Metoestrus } \\
1 \text { and } 2\end{array}$ \\
\hline $\begin{array}{l}\text { Uterine epithelium } \\
\text { Supra-nuclear } \\
\text { Peri-nuclear } \\
\text { Sub-nuclear }\end{array}$ & $\begin{array}{l}++\mathrm{S} \\
- \\
+++\mathrm{S}\end{array}$ & $\begin{array}{l}+\mathrm{S} \\
- \\
++++\mathrm{S}\end{array}$ & $\begin{array}{l}+S \\
+S \\
++S\end{array}$ & $\begin{array}{l}+1++1+++S \\
+1++S \\
+1++S\end{array}$ \\
\hline $\begin{array}{l}\text { Gland epithelium } \\
\text { Supra-nuclear } \\
\text { Peri-nuclear } \\
\text { Sub-nuclear }\end{array}$ & $\begin{array}{l}- \\
- \\
+\mathrm{S}\end{array}$ & $\begin{array}{l}+\mathrm{s} \\
- \\
+++\mathrm{S}\end{array}$ & $\begin{array}{l}+S \\
+S \\
++-\end{array}$ & $\begin{array}{l}+\mathrm{S} \\
- \\
+++\mathrm{S}\end{array}$ \\
\hline
\end{tabular}

Number of vesicles/granules: + , very few; ++ , few; +++ , numerous; ++++ , very numerous. Size of vesicles/granules: S, small $(1 \mu)$.

At di-oestrus, an average of twelve stromal macrophages was found within an area $150 \mu$ from the basement membrane of the uterine epithelium and at oestrus and metoestrus, there were averages of fifty-nine and forty-nine respectively. 
Lipids. At di-oestrus (PI. 2, Fig. 1), small sudanophilic granules are always found along the basal border of the epithelium and usually also in the supranuclear cytoplasm (Table 2). There is an increase in the sub-nuclear sudanophilic granules at pro-oestrus (Pl. 2, Fig. 2) with very few granules present in the supra-nuclear cytoplasm. There is a general reduction in sudanophilic material at oestrus but more granules are found in the peri-nuclear region. At

TABLE 3

A COMPARISON OF THE NUMBERS AND DISTRIBUTION OF PASPOSITIVE GRANULES DURING VARIOUS STAGES OF THE OESTROUS GYCLE

\begin{tabular}{|c|c|c|c|c|}
\hline & Di-oestrus & Pro-oestrus & Oestrus & $\begin{array}{c}\text { Metoestrus } \\
1 \text { and } 2\end{array}$ \\
\hline $\begin{array}{l}\text { Uterine epithelium } \\
\text { Supra-nuclear }\end{array}$ & $\begin{array}{l}++\mathrm{L} \\
+\mathrm{S}\end{array}$ & $+++\mathrm{S}$ & $\begin{array}{l}+\mathbf{M} \\
+++\mathrm{S}\end{array}$ & $++S$ \\
\hline Peri-nuclear & & - & - & $+\mathrm{S}$ \\
\hline Sub-nuclear & $++\mathrm{s}$ & $+s$ & - & $+\mathrm{S}$ \\
\hline $\begin{array}{l}\text { Gland epithelium } \\
\text { Supra-nuclear }\end{array}$ & $++S$ & $+++S$ & $+++\mathbf{S}$ & $t+t S$ \\
\hline Peri-nuclear & $++S$ & $+s$ & $+\mathrm{S}$ & $+\mathrm{s}$ \\
\hline Sub-nuclear & - & - & - & - \\
\hline
\end{tabular}

Number of vesicles/granules: + , very few;,++ few $;+++$, numerous. Size of vesicles/granules: $\mathrm{L}$, large $(3 \mu) ; \mathrm{M}$, medium (1 to $3 \mu) ; \mathrm{S}$, small $(1 \mu)$.

metoestrus, the amount of sudanophilic material in the uterine epithelium varies but the concentration appears to build up from M1 to M2.

At M2, there are discrete collections of small granules in the peri-nuclear region. Most leucocytes in and close to the epithelium have dark sudanophilic granules, although a few have little sudanophilic material.

The glandular epithelium has mainly sub-nuclear sudanophilic granules similar to the luminal pro-oestrus condition and, apart from an apparent lack of sudanophilic material at di-oestrus, this remains fairly constant (Pl. 2, Fig. 5). There is no lipid in the gland lumina. The stromal macrophages seen throughout the oestrous cycle have a diffuse background stain and a few small sudano-

\section{EXPLANATION OF PLATE 1}

FIG. 1. Acid phosphatase activity in the uterine epithelium at di-oestrus. Note large lysosomes. $\times 700$.

Fig. 2. Acid phosphatase activity in the uterine epithelium at pro-oestrus. Note the difference between the supra- and sub-nuclear lysosomes. $\times 700$.

FIG. 3. Acid phosphatase activity in the uterine epithelium at oestrus. Note the general pattern of lysosomes throughout the epithelium. $\times 600$.

FIG. 4. Acid phosphatase activity in the uterine epithelium at metoestrus. This shows late M1 with leucocytes and an accumulation of large lysosomes. $\times 700$.

FIG. 5. Acid phosphatase activity in the glands at oestrus. Note the similarity to prooestrus. $\times 300$.

FIG. 6. Acid phosphatase activity in the glands at pro-oestrus. $\times 600$. 
PLATE 1
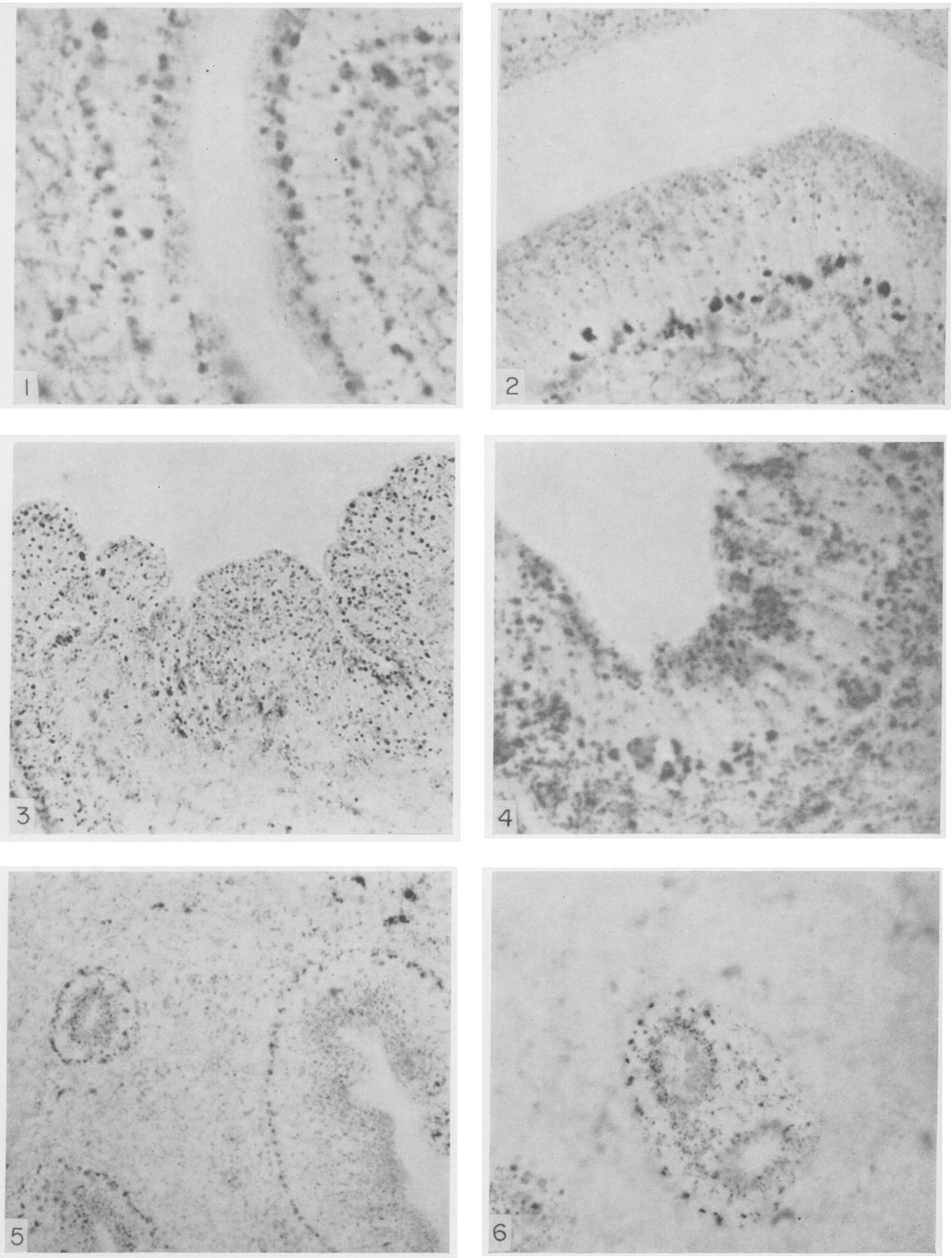

(Facing p. 464) 


\section{PLATE 2}
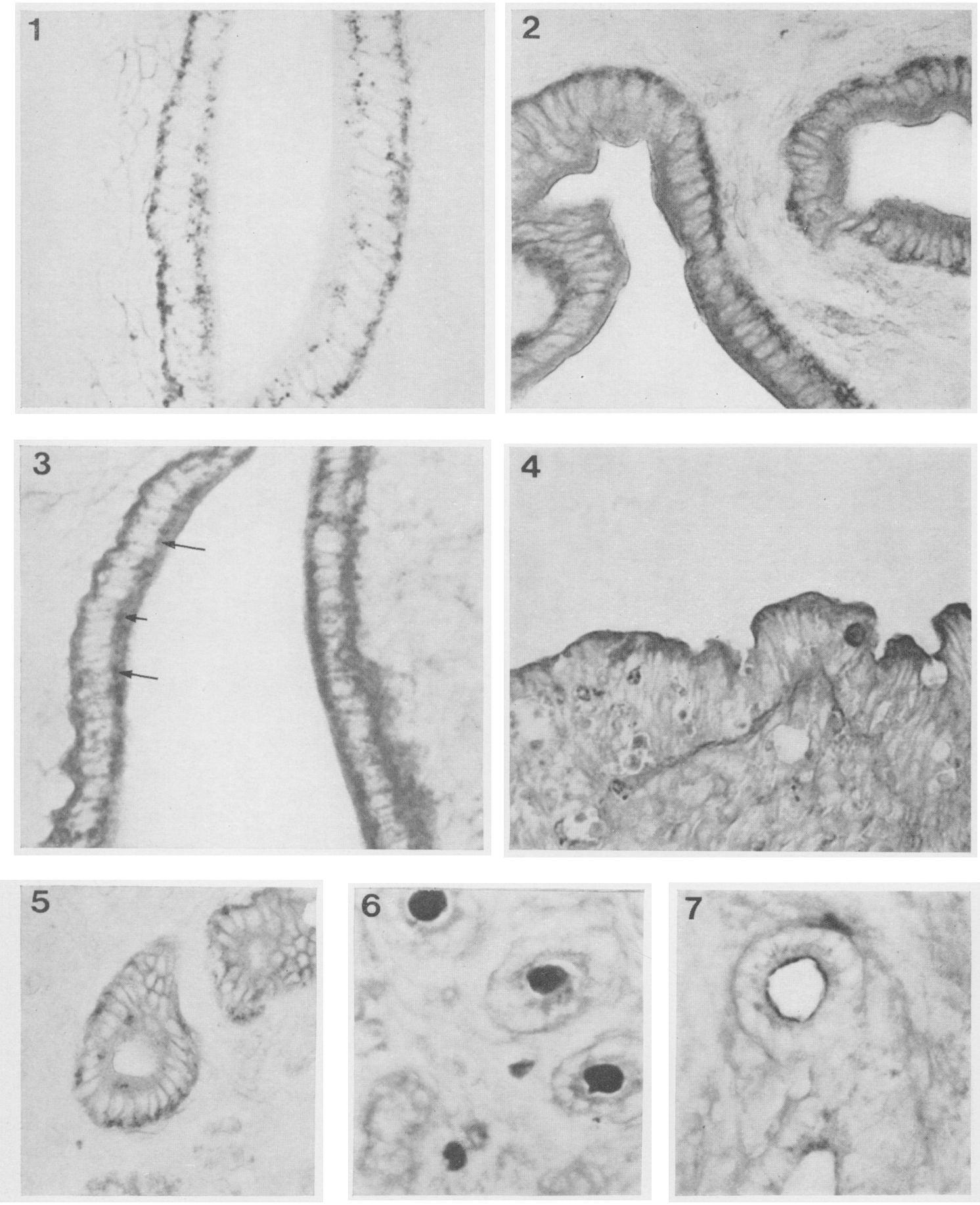

(Facing p. 465) 
philic granules but those with an elongated shape appear to have more sudanophilic material than the large round ones.

Polysaccharide complexes (PAS-positive material). Most of the PAS-positive material found in the mouse uterus during the oestrous cycle is diastase-resistant. The distribution and occurrence of PAS-positive granules is shown in Table 3. At di-oestrus, the uterine epithelium shows a strong PAS-positive reaction in the supra-nuclear cytoplasm but little or no reaction in the subnuclear cytoplasm (Pl. 2, Fig. 3). The supra-nuclear cytoplasm at pro-oestrus is more profuse and more strongly PAS-positive than that in di-oestrus whereas at oestrus, there is a reduction in the PAS-positive staining of the supra-nuclear cytoplasm with the appearance of a few medium-sized PAS-positive granules. During metoestrus, there is only a small area of PAS-positive supra-nuclear cytoplasm, particularly at M1. Many of the vacuoles appear to have a moderately PAS-positive reaction at M2 (Pl. 2, Fig. 4).

The gland epithelia at di-oestrus have no general PAS-positive stain but there are PAS-positive granules in the supra-nuclear regions. Also, most of the gland lumina are filled with a homogeneous PAS-positive plug. At pro-oestrus, there is an increase in supranuclear granules but still none in the sub-nuclear cytoplasm. At this stage, about half of the gland lumina have the characteristic PAS-positive plug (Pl. 2, Fig. 6). The oestrous and metoestrous gland patterns are similar to the pro-oestrous pattern but no plugs are found in the lumina. However, at oestrus, the luminal edge of many glandular epithelia has a homogeneous layer of PAS-positive material attached (Pl. 2, Fig. 7).

The stromal macrophages have numerous PAS-positive granules and at least half have a strong PAS-positive reaction, though it is only at metoestrus that PAS-positive granules become very obvious.

Diastase-digested material. Diastase digestion for $45 \mathrm{~min}$ at $37^{\circ} \mathrm{C}$ produces little change in the PAS-positive staining of sections from pro-oestrus and oestrus. At metoestrus, following diastase treatment, there is a significant decrease in the general PAS-positive stain in the uterine and glandular epithelia, but no change in the granules, which are therefore diastase-resistant. There is also some reduction in the PAS-positive reaction in the epithelia at di-oestrus following diastase digestion.

\section{EXPLANATION OF PLATE 2}

FIG. 1. A section of the uterine epithelium at di-oestrus, stained with Sudan Black B. Note the relative abundance of lipid near the basement membrane. $\times 300$.

FIG. 2. A section of the uterine epithelium at pro-oestrus showing a large amount of lipid in the sub-nuclear cytoplasm. Stained with Sudan Black B, counterstained with Saffranin O. $\times 300$.

Frg. 3. A section of the uterine epithelium at di-oestrus stained with periodic acid-Schiff (PAS). Note the large granules in the supra-nuclear cytoplasm (arrow). $\times 300$.

FIG. 4. A section of the uterine epithelium at metoestrus. This shows the epithelial breakdown at M2 plus many large round PAS-positive bodies, possibly leucocytes. $\times 600$. FIG. 5. The distribution of lipid in the gland epithelium at pro-oestrus, stained with Sudan Black B. $\times 300$.

FIG. 6. The distribution of PAS-positive granules and the homogeneous PAS-positive plugs in the gland lumina at di-oestrus and pro-oestrus. $\times 300$.

FIG. 7. The distribution of PAS-positive granules in the gland epithelium and the attachment of the homogeneous PAS-positive layer to the lumen edges at oestrus. $\times 300$. 


\section{DISCUSSION}

The histology of the cyclic mouse uterus has been studied by various authors (Allen, 1922; Bronson et al., 1966). The general histological changes seen in this study are similar to those presented by these authors. The uterus has been shown to undergo anabolic and catabolic changes which appear to be more clearly demonstrated in formalin-fixed frozen sections than with routine histological techniques.

The acid phosphatase-rich lysosomes show a distinct series ranging from mainly large ones at di-oestrus, many small supra-nuclear ones at pro-oestrus and an overall distribution of small ones in the uterine epithelium at oestrus. The distribution of small lysosomes at pro-oestrus and oestrus appears to be associated with uterine cell growth and, as shown by Fuxe \& Nilsson (1963) who examined the histology of the mouse uterus, the maximum secretory activity is at oestrus. During the breakdown of epithelial cells at metoestrus, there appears to be an accumulation of large lysosomes. These may be similar to the small lysosomes, which have probably been recently synthesized and are found mainly in the anabolic stages but containing more hydrolytic enzymes, or they may have a different function. There is no evidence for the release of acid hydrolases in intact cells, although their release in tissue homogenates is well established (De Duve, 1963; Gahan, 1967); but the large lysosomes at metoestrus and di-oestrus may be indicative of some enzyme release. Therefore, acid hydrolases appear to be synthesized in the anabolic stages and accumulate in the catabolic stages.

The PAS-positive and sudanophilic granules are not the same as the lysosomes except at di-oestrus, when some large PAS-positive granules may correspond to the large lysosomes. Bronson et al. (1966) have stated that the glycogen content is greatest in the mouse uterus at pro-oestrus but because they have not recorded their method of glycogen detection, the result is not comparable with the presence of glycogen at met- and di-oestrus in this study. It may be that glycogen is utilized by the cell during growth and is only obvious during the catabolic phases. Di-oestrus and pro-oestrus are the major secretory periods in the glands. There is considerable acid phosphatase activity at the luminal border at dioestrus and glycoprotein or mucoprotein is found in the gland lumina. This material is also found at oestrus, attached to the lumen borders. In the dog, Erichsen (1953) and Fitch (1963) showed the presence of PAS-positive plugs at pro-oestrus, oestrus and metoestrus which demonstrates a different activity phase to the mouse.

The occurrence and distribution of lipids in the uterus does not generally follow a clear pattern. Erichsen (1953) could not show lipid in the canine uterus during the oestrous cycle. The cat also has no lipids at oestrus (Dawson \& Kosters, 1944). The mouse has abundant lipid at di-oestrus and pro-oestrus and especially metoestrus, but very little at oestrus. The role of lipids in the uterus is as yet unknown but the increase of lipid in the mouse uterine epithelium at metoestrus may be indicative of cellular degeneration.

This work was supported by a fellowship from the Wellcome Trust whose help 
I gratefully acknowledge. I wish to thank Dr D. Pugh and Dr I. B. Wilson for their help and advice.

\section{REFERENCES}

Allen, E. (1922) The oestrous cycle in the mouse. Am. 7. Anat. 30, 297.

Bronson, F. H., DagG, C. P. \& Snell, G. D. (1966) Reproduction. In: Biology of the Laboratory Mouse, chap. 11. Ed. E. L. Green. McGraw-Hill, New York.

Burstone, M. S. (1958) Histochemical comparison of naphthol as phosphates for the demonstration of phosphatases. 7. natn. Cancer Inst. 20,601.

De Duve, C. (1963) The lysosome concept. In: Lysosomes. Ciba Foundation Symposium. Eds. A. V. S. de Reuck and M. P. Cameron. Churchill, London.

Dawson, A. B. \& Kosters, B. A. (1944) Preimplantation changes in the uterine mucosa of the cat. Am. F. Anat. 75, 1.

ERICHSEN, S. (1953) Histochemical changes in the endometrium of the dog during the oestrous cycle. Acta path. microbiol. scand. 33, 263.

Frtch, K. L. (1963) A study of uterine glycogen during the oestrous cycle of the dog. 7. Morph. 113, 331.

Fuxe, K. \& Nrlsson, O. (1963) The mouse uterine surface epithelium during the oestrous cycle. Anat. Rec. 145, 541 .

GaHan, P. B. (1967) Histochemistry of lysosomes. Int. Rev. Cytol. 21, 1.

Pearse, A. G. E. (1960) Histochemistry, theoretical and applied, 2nd edn, pp. 850, 832. Churchill, London. 